\title{
Causes of Construction Delays in Different Buildings Typology in Portugal
}

\author{
António Brito* \\ Department of Civil Engineering, Campus Universitário de Santiago, 3810-193 Aveiro, Portugal
}

*Corresponding author: António Brito, Department of Civil Engineering, Campus Universitário de Santiago, 3810-193 Aveiro, Portugal.

Received Date: March 12, 2021

Published Date: April 08, 2021

\begin{abstract}
The construction represents the sector with the higher impact in the world economy, representing $13.4 \%$. This sector, crucial to the socioeconomic stability of a country, has been several affected due to the successive construction delays in the design as well as execution phases. Additionally, in comparison with other sectors, the construction industries present lower receptivity in the development of new methodologies and technologies to increase the competitiveness as well as workers incomes and profits increasing the attention from the industry and academia. This study focusing the identification of the constructions processes, which leaves to their delays. Thus, three different buildings typology use were studied (in a real ambient), to identify the delays by groups, type and category to achieve a deep understanding and recommendations to help companies and owners to reduce the risk of delay during the execution phase. Regarding the findings the management domain scheduling work is a simple way to predict the length of deadline and to carry out its control. However, the issue with higher impact in the overall construction delay is related with the lack of a detailed planning as well as works programs and constraints study leading to a several issues in the execution phase that could been previously avoided. As a final conclusion the critical path analysis system is the most used for project management in construction, however new softwares to optimise these programs in order to reduce the extension of deadlines, increase the competitiveness of the sector and consequently its profits is paramount of importance.
\end{abstract}

\section{Introduction}

The construction sector has a significant influence on the world's economy, representing a total of 176 billion euros, in 2017, for European International Contractors members [1]. The 2008 economic crisis [2] highlighted the asymmetries between large and small to medium- sized companies in the construction industry business fabric and led to profound changings within construction companies, thus determining a new paradigm in the sector. Small companies were forced to declare insolvency, and large corporations began to operate almost exclusively through subcontracting, as a strategy to reduce the cost structure as well as the means of reducing fixed costs. The consequent adjustment to the business model in the construction industry resulted in large corporations to become increasingly dependent on outsourced entities for the construction activities to be performed

[3], therefore representing one of the main reasons identified in literature for the construction delays to occur [4-5]. Additionally, the shortage of qualified labor workmanship does not allow several execution designs to be perfectly concluded [6-7]. The existence of errors and/or omissions in design phase often provides delays that lead to prolonged interruptions in the work, as well [8], and the increasing competitiveness of the sector, related to the existence of more construction companies than the actual market demand, is responsible for the diminishing of profits [9]. The awareness and identification of which specific constraints are responsible for the construction delays is paramount for the business market, so that construction corporations do remain competitive as well as holding profit. The economic factors of the region or country in which it operates can change the motivation of the entities involved 
[10]. Kumar and Narayanan [11] in their research evaluated the different risk factors that affect the execution deadline in the construction sector by distributing a questionnaire survey. Thus, a risk management procedural index was evaluated that allows to obtain the percentage of risks as well as their respective rank in order of the weighted value. Regarding results the highest delays were observed in the management with $15 \%$ of risk, financial with $12 \%$ and finally environmental causes with $10 \%$ of risk.

Several studies discussing the risk of delays have been studied extensively in the literature. Focusing by category (non-extensive list) the type of risk is following detailed: Financial risk including contract risk, delay caused by the contractors, increase of the price of the construction materials and the bank orders changing [1215]. Management risk namely, poor, or improper planning and communication, external and internal collaboration, design errors and ineffective teamwork [16-20]. Technical risk namely, lack of training, low wages, inadequate safety measures in the execution, physical obstructions, frequent changes in the design, poor quality of materials [21-24]. Legal and political assessment comprising, errors in the contract documents, legal terms and procedural landscape, improper documentation, lack of records, loss of revenue by the state, undefined bureaucracy and corruption in the construction sector [25-29]. Environmental impact, such as natural resources management, noise pollution, air pollution, health plans development, and ecosystems [30-32]. From the above selected literature review, significant importance has been presented on the identification of the critical causes of delays in the construction sector. However, a sequential dependence as well as the influence on the delay of tasks or sub tasks over others has not widespread reporting. Thus, it is paramount of important to identify and to study the relationship between the critical tasks as well as identifying the relationship between the delays and for instance make predictions on the impact in the subtasks.

In the present research it has been identified several construction processes responsible for time delays using as a case study real scale under construction at the time. Thus, it has been detailed analysed the work that has been done in three different buildings with distinct constructive typologies, in order to better understand the type of constraints associated with each typology accordingly to [33]. Subsequently, once the constraints were identified, they were grouped and categorized by the time delay and constraint category respectively [34-35]. Finally, its evaluation has been performed considering which factors influenced the extension of the construction deadline [36]. In the present research it has been identified various construction processes responsible for time delays in real scale case studies. Furthermore, it has been closely analysed the work that has been done in three different buildings with distinct constructive typologies, in order to better understand the type of constraints associated with each typology [33]. Subsequently, once the constraints were identified, they were grouped and categorized by the time delay and constraint category respectively [34-35]. Finally, its evaluation has been performed considering which factors influenced the extension of the deadline [36]. The starting point of this work starts within an internship at Constructora San José SA [37] focusing on the reduction of delays and to recover the execution times towards respecting the deadlines established, allowed the identification and collection of the real constraints responsible for the consequent delays. Thus, a novel approach has been developed to estimate the time delays through case studies analysis, facing the real problems occur as well as solutions, in real environment during the execution phase, in-situ. In summary, the objective of this paper is to provide an effective methodology focused on the reduction of delays in the construction industry work, through providing effective solutions able to predict the constraints and subsequently to mitigate their impact on execution times with a direct evaluation on the relationship between tasks and sub-tasks.

\section{Methodology}

The followed methodology begins with the identification of the most common delays referred in the literature. Grouping the identified delays into different categories is the first step of the present work. The implemented methodology to assess the causes of delays in constructions is divided into five main steps:

\section{Step 1-Causes of delays in construction}

Case studies characterization and respective identification of the construction delays. It starts with the building's characterization, in terms of typology, location and execution deadlines. Then, the critical activities of the three case studies have been identified, assessing the differences in the construction techniques and its influence in the respective construction delays.

\section{Step 2-Cases studies general characterization}

The constraints were categorized into different groups in order to quantify the most critical delays considering the global construction deadline. For this case study, two buildings were evaluated retrospective, and one was followed in real time ("The Largo Hotel").

\section{Step 3-Development of a new methodology}

Development of a new methodology to identify critical tasks in the construction delays and evaluated them in the context of "The Largo Hotel" construction. This procedure attempt to quantify risks responsible for delays that occur within a specific task, as well as its impact on the overall construction schedule.

\section{Step 4-Criterion analysis and evaluation}

The successful implementation of this methodology was very helpful to identify critical tasks related to delays. Due to those delays, it's also important a de- tailed criterion that allows the identification of activities that might causes delays in the constructions. Therefore, this step intends the evaluation of criteria activities typical used on buildings. Then an evaluation of "The Largo Hotel" case was developed. 


\section{Step 5-Conclusion}

In the final step, a list of recommendations is pro- vided with the intention of aiding designers, constructors, and owners through the process of planning the construction activities by means of facilitating the identification of the issues and constraints that result in serious delays during execution phase.

The methodology can be schematically depicted in Figure 1 (Figure 1).

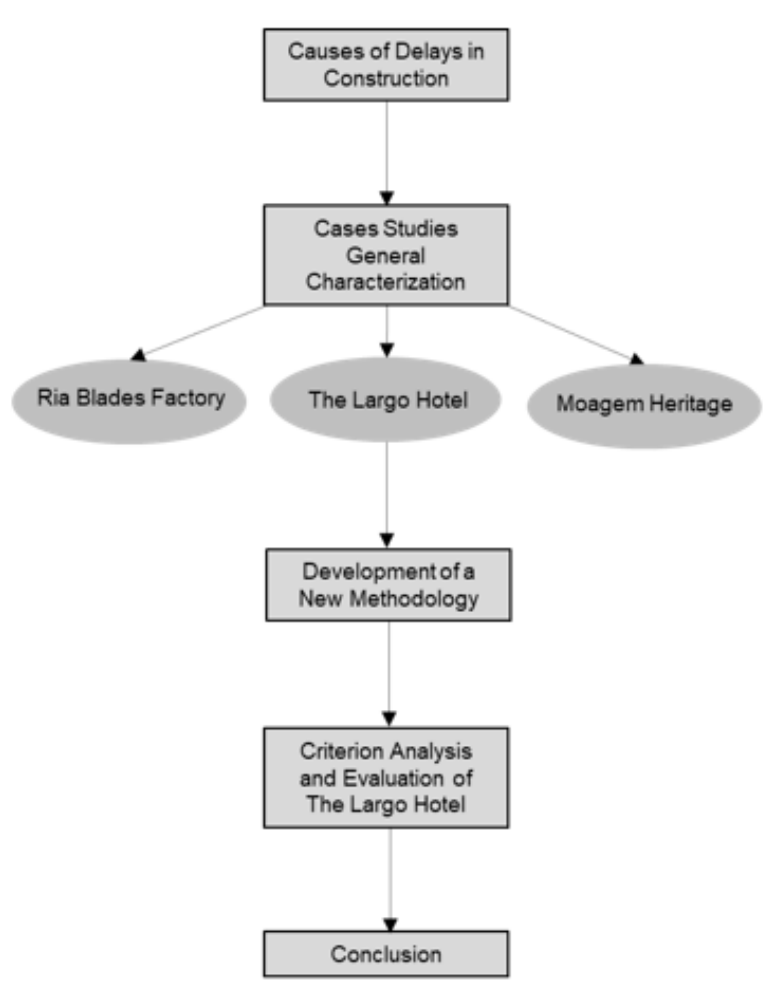

Figure 1: Methodology Followed.

\section{Construction Delays}

\section{Constraint's categories}

Delays can be classified in terms of liability into three groups. The excusable give the contactor the right extra time to complete the work, and they are caused by the owner. Additionally, the nonexcusable are delays that do not entitle the contractor to extra time to complete the work nor additional monetary compensation. Lastly, concurrent delays are caused by external factors, such as the COVID-19 pandemic (Figure 2).

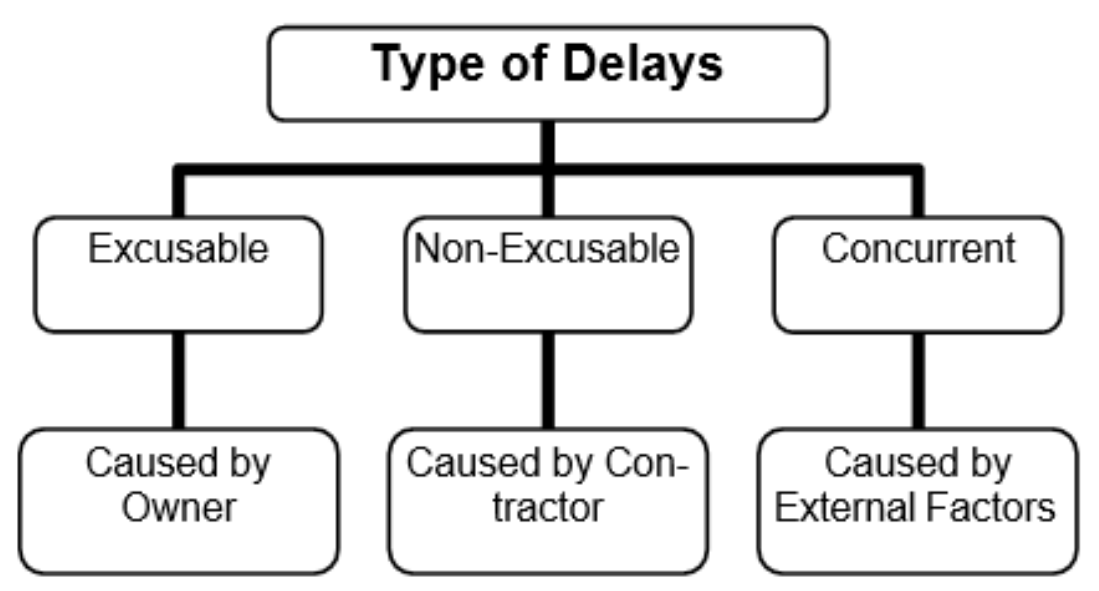

Figure 2: Type of Delays in Construction. 
Construction delays are recurrent events in civil construction works and there is still no effective solution to prevent and mitigate their effects. Numerous authors have written about this problem, referring several countries and different types of construction activities, ranging from the design phase to the execution phase [38-39]. In order to mitigate construction delays, it is important to categorize the various constraints into different groups [40]. This is depicted in Table1.The category of constraints related to external factors is the only one uncontrollable [41], since random and unpredictable events, outside the influence of the participants, are possible to happen [42], as COVID- 19 pandemic, fires, floods, strong winds. A much broader breakdown was proposed in this study, in which eight groups were identified, such as: materials (MT), equipment (EQ), labor (L), owner (O), consultor (CO), designers (D) and contractors (C) (Table1).

Table 1: Constraints Categories.

\begin{tabular}{|c|c|}
\hline \multicolumn{2}{|c|}{ Constraints Categories } \\
\hline Abbreviation & Identification \\
\hline MT & Materials \\
\hline $\mathrm{EQ}$ & Equipment \\
\hline $\mathrm{L}$ & Labor \\
\hline $\mathrm{O}$ & Owner \\
\hline $\mathrm{CO}$ & Consultor \\
\hline $\mathrm{D}$ & Designers \\
\hline $\mathrm{C}$ & Contractor \\
\hline $\mathrm{EF}$ & External Factors \\
\hline
\end{tabular}

\section{Identification of delay types}

Construction delays are generally defined as the additional time required for the contractor to complete the work, in comparison to the original schedule agreed with the owner [33]. Additionally, construction design involves large quantities of capital, as they comprise professionals from different areas, technology, machinery and equipment, and considerable funds. In this sense, every additional time needed for complete the design implies capital and investment losses [39]. Due to the abovementioned factors, it is paramount to classify delays by type in order to minimize the overall construction schedule [43]. The excusable delay can be compensable or non- compensable [34-35]. Whether or not a delay is compensable depends primarily on the terms of the contract. In many cases, the contract specifically defines the kinds of delays that are excusable, non- compensable, for which the contractor does not receive any additional money but may be allowed a time extension [34].

\section{Cases Studies}

\section{Case's studies location}

To identify all the constraints responsible for introducing delays in the time execution of works, a novel approach have been developed for the three cases studies, all from different typologies, as defined in section 2 (see section 2), and regions in Portugal mainland. The buildings' typology was studied to analyse the possibility to different constraints to happen, or if related constraints were the same between the different cases. One of the constructions was a hotel development located in the centre of Oporto, "The Largo Hotel", as depicted in Figure 3A, in which the real-time monitoring was carried, with the objective of pursuing and understand which problems arise during its execution and the consequent constraints that could lead to a deadline extension. The second case study is an industrial facility located in Aveiro Region named "Ria Blades Factory", Figure 3B. As third case study, a building intended for residential purposes, commerce, and services located in Leiria, identified as "Moagem Heritage", Figure 3C. These last two (Ria Blades Factory and Moagem Heritage) were finished works that had extension of deadline and, therefore, the study was made retrospectively in order to identify delays. Despite all different in terms of characteristics, it is extremely important to define what constraints have are common between the different constructions, and which differ from one to another, in order to assure compliance of deadlines (Figure 3).

\section{Case studies characterization}

The largo hotel: The construction site is located, in the Porto urban centre. In Figure 4 it is shown the satellite image of the location (Figure 4, Source Google Earth). The execution time in the contract was of 184 days, with the starting date of $05 / 08 / 2019$ and ending date to be $16 / 04 / 2020$. The extension deadline was 40 working days (Figure 4)

Ria blades factory: The construction site is located in Aveiro region, the following figure depicts the satellite image of the site (Figure 5, Source Google Earth). For this construction, the execution time intended had been defined to be 183 working days, starting from the April 14th of 2014 and ending on December 30th of 2014. Instead, it has been concluded with a delay of 70 working days (Figure 5). 


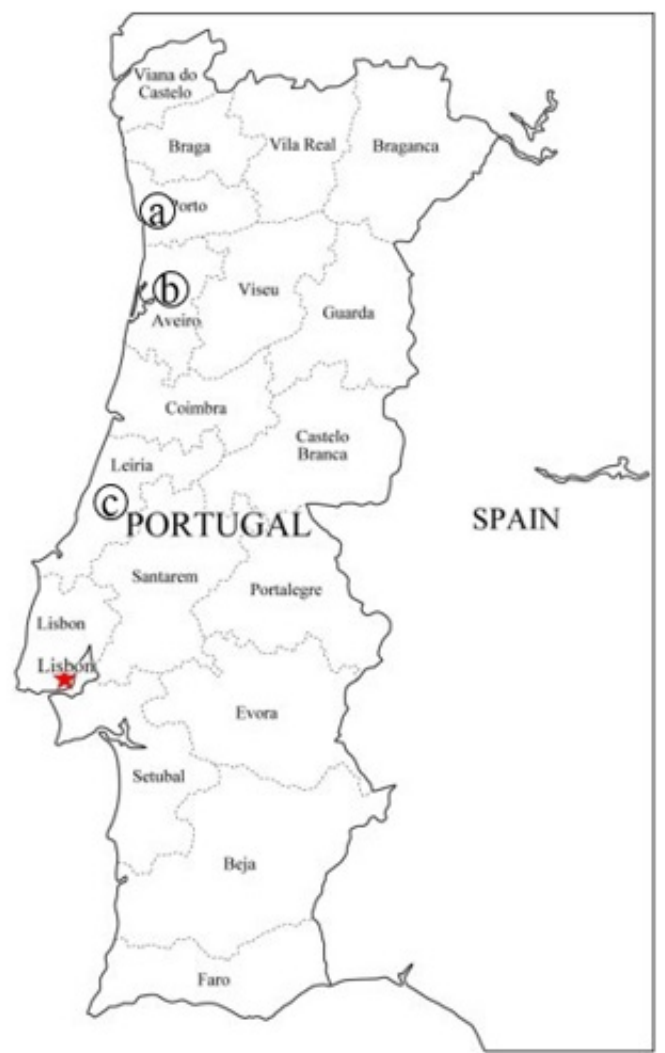

Figure 3: Cases Study Location: a) The Largo Hotel; b) Ria Blades Factory; c) Moagem Heritage.

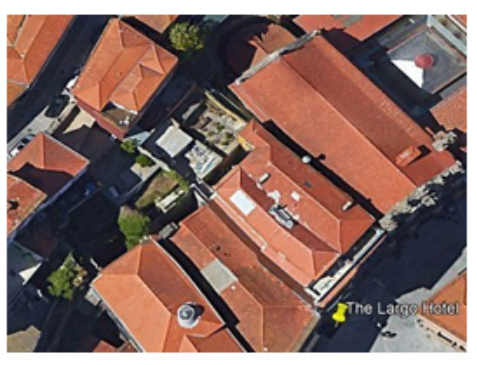

Figure 4: Satellite Image the Largo Hotel.

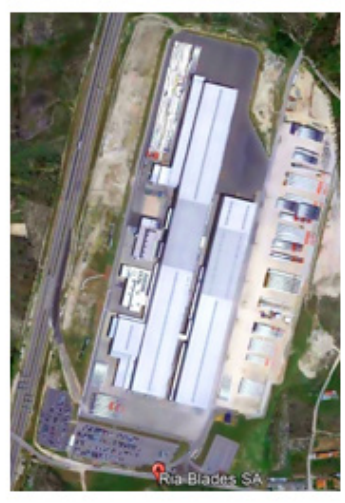

Figure 5: Satellite Image Ria Blades Factory. 
Ria blades factory: The construction site is located in Aveiro region, the following figure depicts the satellite image of the site (Figure 5, Source Google Earth). For this construction, the execution time intended had been defined to be 183 working days, starting from the April 14th of 2014 and ending on December 30th of 2014. Instead, it has been concluded with a delay of 70 working days (Figure 5).
Moagem heritage: The construction site of the "Moagem Heritage" is located at Leiria region, as presented in the satellite image of Figure 6, acquired from Google Earth software. Regarding the schedule of this construction, it was expected to start on September 7th of 2015 and to end on June 5th of 2017, comprising a total of 446 work- ing days. However, the execution deadline has been extended by 160 working days (Figure6).

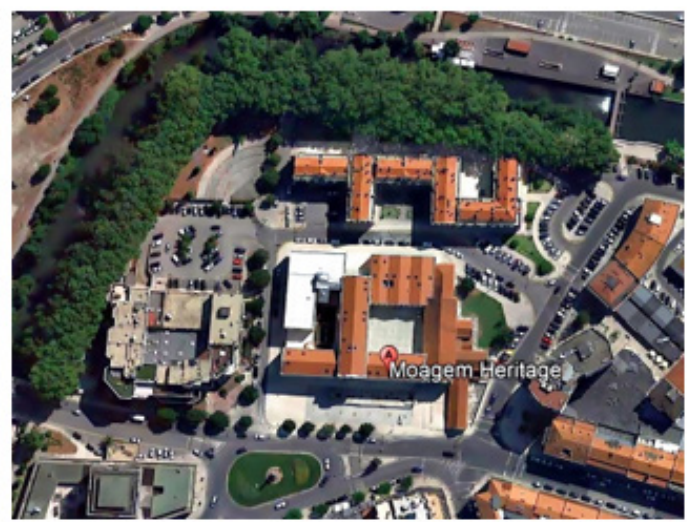

Figure 6: Satellite Image the Largo Hotel.

\section{Construction plan}

In this section the activities of the three case studies were identified, with the purpose of understand- ing the differences between them. The only identified common activities shared by the three were: demolition work, foundations and steel structure.
This high- lights the differences among the three case studies. Architecture and project design were not considered in the "The Largo Hotel" since the aim of this research focuses the construction phase and not the design phase. The main tasks of the three cases studies are represented in Table 2 (Table 2).

Table2: Construction Plan Summary.

\begin{tabular}{|c|c|c|c|}
\hline Task Name & The Largo Hotel & Ria Blades Factory & Moagem Heritage \\
\hline Architecture and Design & & $\times$ & $\times$ \\
\hline Demolitions & $x$ & $\times$ & $\times$ \\
\hline Electrical Installations & & $\times$ & $\times$ \\
\hline Elevators & & & $x$ \\
\hline Excavation & $x$ & $\times$ & \\
\hline Facade Support & $\times$ & & \\
\hline Floors & & & $\times$ \\
\hline Foundations & $x$ & $x$ & $\times$ \\
\hline Metal Structure & $x$ & $x$ & $x$ \\
\hline Micropiles & $x$ & & \\
\hline Munich Walls & $\times$ & & \\
\hline Outdoor Arrangements & & & $\times$ \\
\hline Peripheral Containment & & & $\times$ \\
\hline Reinforced Concrete Structure & & $\times$ & $\times$ \\
\hline Tunnels & $\times$ & & \\
\hline Water Drains & & $\times$ & \\
\hline Water Network & & & $x$ \\
\hline Waterproofing System & $x$ & & \\
\hline Wood Structure & & & $\mathrm{x}$ \\
\hline
\end{tabular}




\section{Constraint's impact}

Considering the three case studies analysed, a statistical treatment has been performed to the acquired data. Subsequently, it has been determined which constraints category caused the higher impact on de- laying the scheduled deadline. It has been observed that the category of materials, for the three case studies, had no impact in construction delays. The percentages in the Figures 7-9 were calculated taking into account the expected execution time and the real time that took to execute Then was identified which category was responsible for this delay.

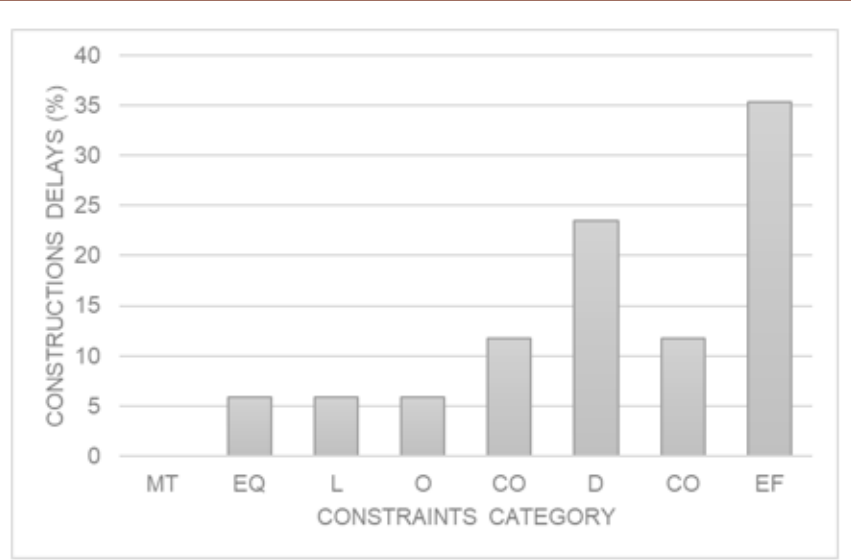

Figure 7: Constraints Categories the Largo Hotel.

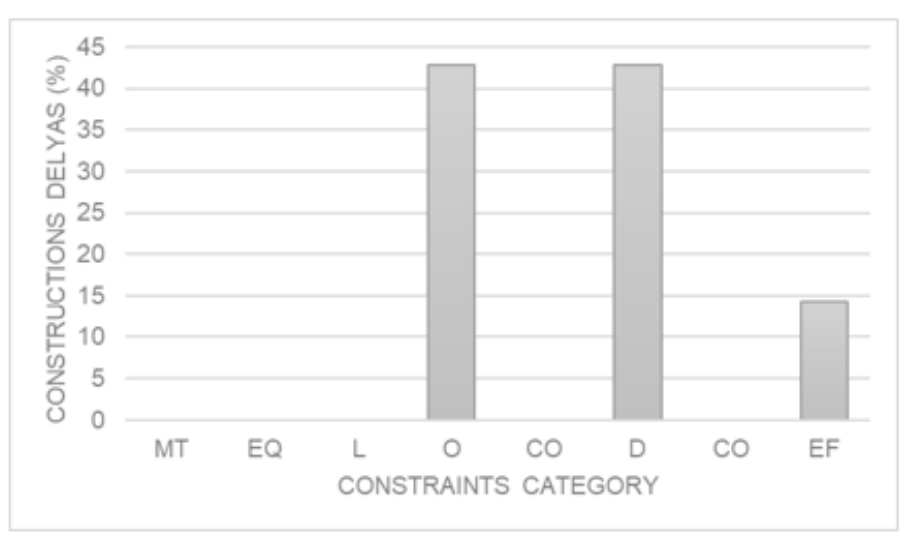

Figure 8: Constraints Categories Ria Blades Factory.

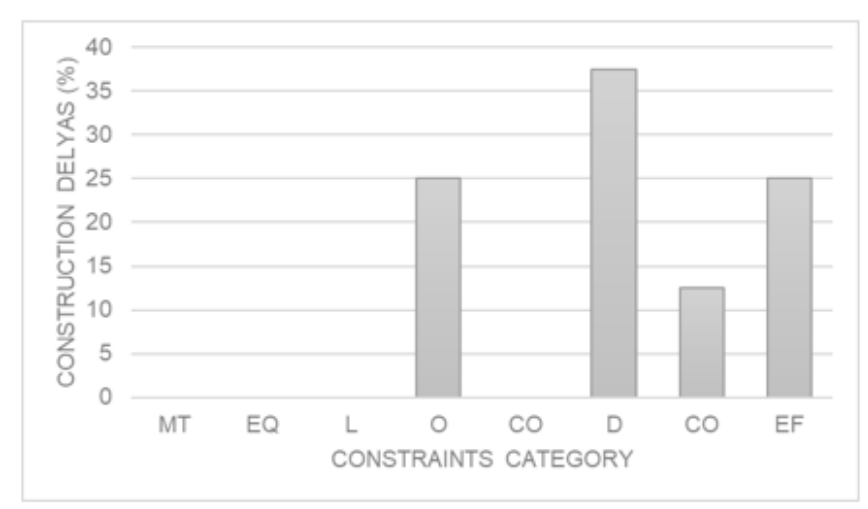

Figure 9: Constraints Categories Moagem Heritage.

The largo hotel: The main constraints categories that caused delays in "The Largo Hotel" deadline were the external fac- tors and designers. These categories are very distinct since the constraints related to designers are likely to be easily solved, while external 
factors, for the most scenarios are practically impossible to predict such as COVID-19 pandemic. Their mitigation is extremely important in order to minimize its impact on execution time (Figure 7).

The main constraints categories that caused delays in construction "The Largo Hotel" were the external factors and the designers.

Ria blades factory: In this type of project, the most important objective in the owner's perspective is to complete the construction as fast as possible for the project to be a profitable investment. Despite the requirement of adequate time to successful finish the tasks, as well as specialized labor, for this typology of project those factors revealed of insignificant importance in terms of impact on time schedule accomplishment (Figure 8).

The essential constraints categories responsible for delays in "Ria Blades Factory" were the owner and again the designers. this occurs since it was an industrial building and, in these cases, the owner objectives are different from other buildings typologies. moagem heritage: The major constraints categories responsible for delays in "Moagem Heritage" were designers, external factors and owner. In comparison with the previous graphic (Figure 8), the categories of designers and external factors remain with a large percentage. However, in this case, the owner is also responsible for a high percentage of construction delay. Due to the typology of the project, a multi-family residential building, this constraint category has a superior per- centage and consequently a greater influence on work schedule delays.

In this type of buildings, the finishes work is frequently retarded, specially comparing to industrial buildings, since they required more complexity (Figure 9).

Furthermore, it is possible to understand that designers and external factors categories had a great impact on the works delays of all case studies.

\section{Evaluation Methodology}

The results obtained were critical to the tasks evaluation in the "The Largo Hotel" case study which took into account ten criteria. Each criterion oscillates in a range between one and ten, which "1" represents "insignificant im- portance" and " 10 " means "extremely importance", acting as a rating scale. The minimum rating for a task is " 10 ", which means a very low risk of delays and " 100 " means a great risk for the occurrence of delays. The evaluation methodology can be schematically depicted in (Figure10).

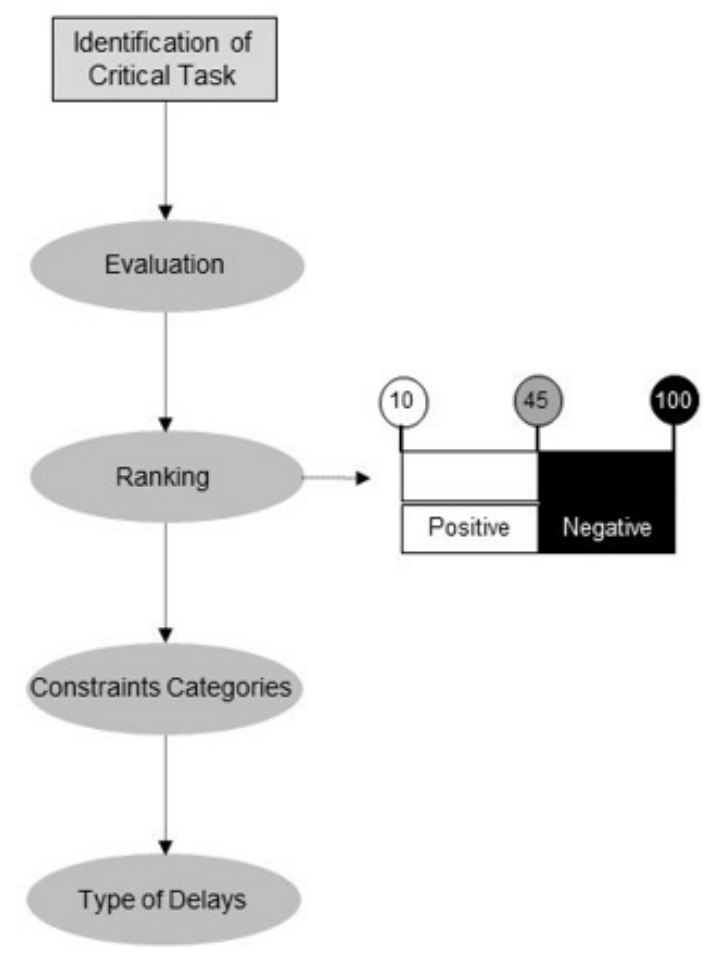

Figure 10: Evaluation Methodology.

In this graphic (Figure 11), it represents a type of delays percentage (Figure 11).

The type of delays that are most likely to occur are both nonexcusable and excusable. The first type is directly or indirectly attributed to the contractor, while the same situation is also valid to the owner in the cases of excusable type. In this graphic (Figure 12), it represents a type of delays percentage (Figure 12). 


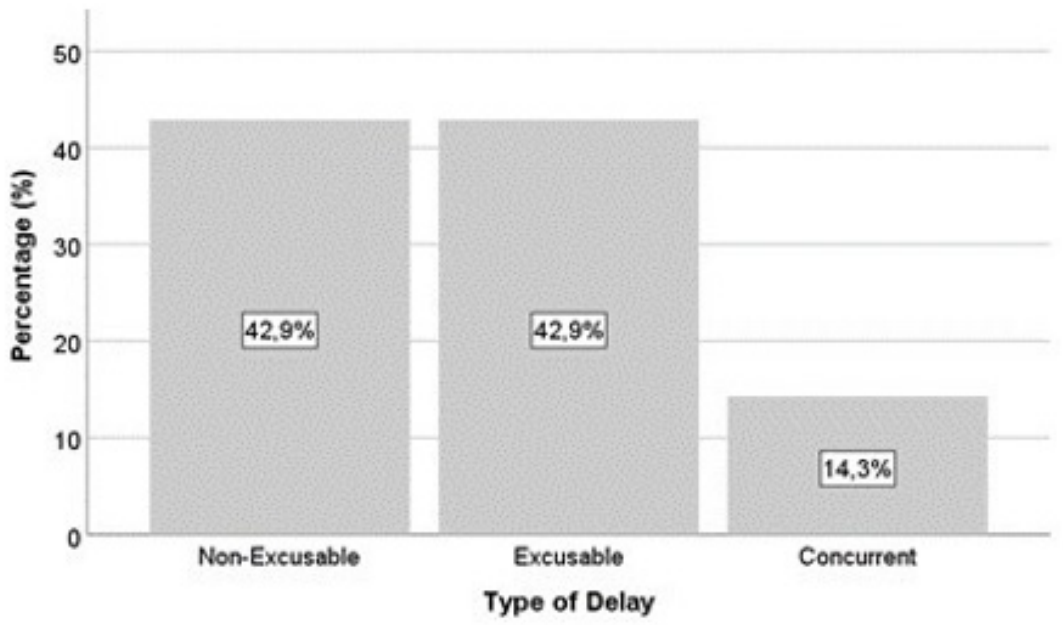

Figure 11: Type of Delays Percentage.

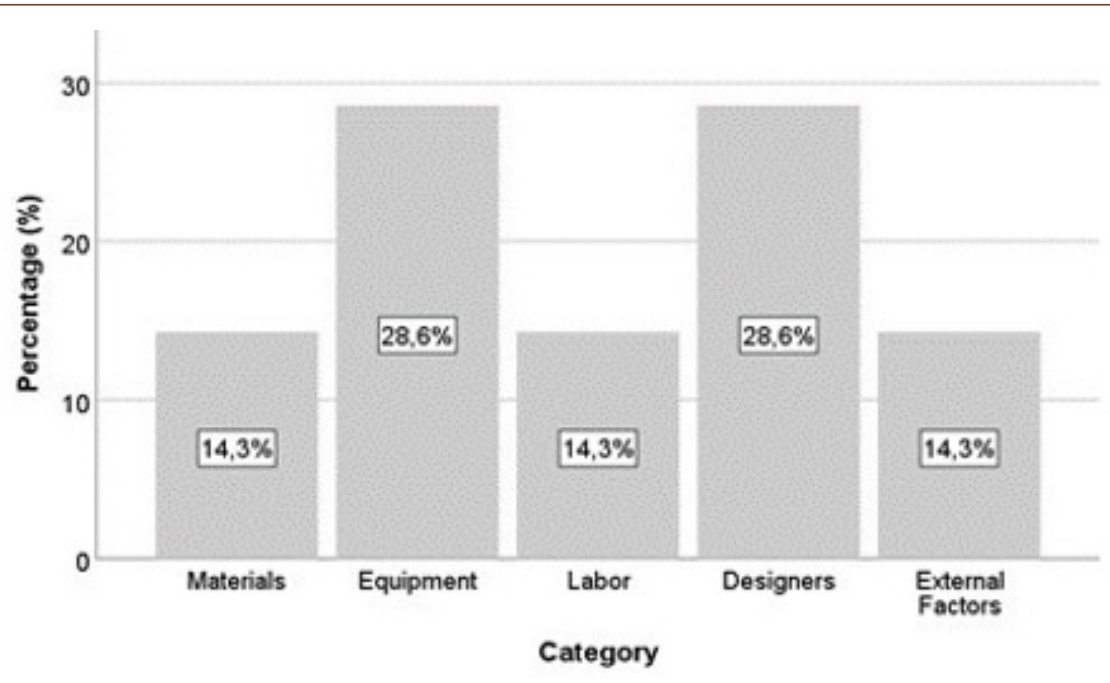

Figure 12: Category of Delays Percentage.

Since it is of significant difficulty in quantifying the evaluation in the category of delays' percentage, owner, consultor and contractor were not considered directly. Furthermore, classification by type of delays allows contractor to be held responsible for retarding the deadline in tasks such as materials, equipment, and labor. The delays associated with designers and consultors can be imputed to the owner since these categories are the owner's decision. The categories of delay that are most likely to occur are equipment and designers. The equipment category can be attributed to the contractor, while de- signers' errors and/ or omissions are the owner's responsibility, as shown in Figure 12. It should be mentioned that the external factors, despite its low percentage, are generally a category that presents several variables difficult to quantify. Often, it is difficult to predict what the real impact of external factors on the work schedule will be.

\section{Results}

\section{Criterion analysis}

In order to perform the evaluation, it has been necessary to develop criteria that could carefully identify which activities are responsible to cause an extension of the established deadline to conclude the work. Furthermore, in this case study, it has been of concern to the authors that the defined criteria and methodology would be able and suitable to be used in the majority of the civil construction works.

The assessment criteria established was:

1. Cash Flow Statement (CFS): If the contractor has high financial power, it has a greater economic capacity to be able to have all materials, equipment and subcon- tractors prepared and ready for the expected start of every task. 
2. Period Task: for a period of execution of more than one hundred working days, the highest risk of delay is associated to the task.

3. Constructor Knowledge: when the contractors have a know-how that allows to identify the various conditions of a task and the experience with the execution, it represents a factor that can avoid delays.

4. Consultor: it is the bridge between the own- er and the constructor

5. Construction Location: The yields of a work in a country and urban environment are different due to the existing of different constraints. In a country environment usually, the yields are higher.

6. Subcontractors: For more than one contractor, a higher risk of delay is to be considered, because lack of coordination

Table 3: Evaluation Criteria Values.

\begin{tabular}{|c|c|c|c|}
\hline \multirow{4}{*}{ Positive Evaluation } & \multicolumn{2}{|c|}{ Criteria } & Negative Evaluation \\
\hline \multirow{4}{*}{$1-5$} & Yes & Cash Flow Statement & No \\
\cline { 2 - 4 } & $<100$ Working Days & Period Task & $>100$ Working Days \\
\cline { 2 - 4 } & Yes & Constructor Knowledge & No \\
\cline { 2 - 4 } & Active & Consultor & Passive \\
\cline { 2 - 4 } & Country & Construction Location & Urban \\
\cline { 2 - 4 } & $\leq 1$ & Subcontractors & $>1$ \\
\cline { 2 - 4 } & $<3$ & Equipment Number & $\geq 3$ \\
\cline { 2 - 4 } & Well done & Execution Design & Poorly Execution \\
\cline { 2 - 4 } & Industrial & Building Typologies & Familiar or Touristic \\
\cline { 2 - 4 } & Commons & Material Types & Non-Commons \\
\hline
\end{tabular}

\section{Criterion evaluation}

The results of the construction "The Largo Hotel" was represented in these case study because it was the one that was followed in real time. The majority of the tasks were analysed prior to their completion because of already exiting delays. Additionally, COVID-19 pandemic situation led to longer delays on schedule and therefore prolonged the construction deadline. In this sense, and poor communication between the teams is possible to happen, for successfully per-form the same task simultaneously.

7. Equipment Number: When more than three equipments are required to perform specific tasks, it represents a higher risk of delays.

8. Execution Design: when the execution de- sign is poorly executed, can cause significant delay in performing the respective tasks.

9. Building Typologies: In industrial buildings, yields on most cases are higher in contrast with family and tourist developments.

10. Material Types: Can be divided into two groups: common and non-common. The last comprises a greater risk of delay.

In next table (Table 3), it represents a criteria evaluation value (Table 3).

Table 4: Critical Task Ranking.

\begin{tabular}{|c|c|}
\hline Critical Task & Evaluation \\
\hline Munich Walls & 54 \\
\hline Foundations & 53 \\
\hline Excavation & 47 \\
\hline Tunnel & 43 \\
\hline Facade Support & 33 \\
\hline Disassembly of Construction Site & 30 \\
\hline Provisional Reception & 29 \\
\hline
\end{tabular}


The tasks identified with the highest risk of delay were the excavation, foundations, and the Munich walls (Figure 13). It is also important to monitor the tunnel task, as the evaluation value should not surpass forty-five on the previous scale (Figure 13).

The excavation and the tunnel tasks were not as- signed to the contractor, however the Munich walls and foundations were. The Munich walls are the task that presents the greatest risk of delay due to its constructive complexity. Additionally, due to the unusual waterproofing system adopted by the design team, the type of soil and yields are not those that were foreseen in the preliminary work program. Because of that, the foundations needed specific equipment for this specific task, Additionally, there were water and sewage networks in the surrounding area, which required special care in order to avoid damaging the existing pipes (Figure 14).

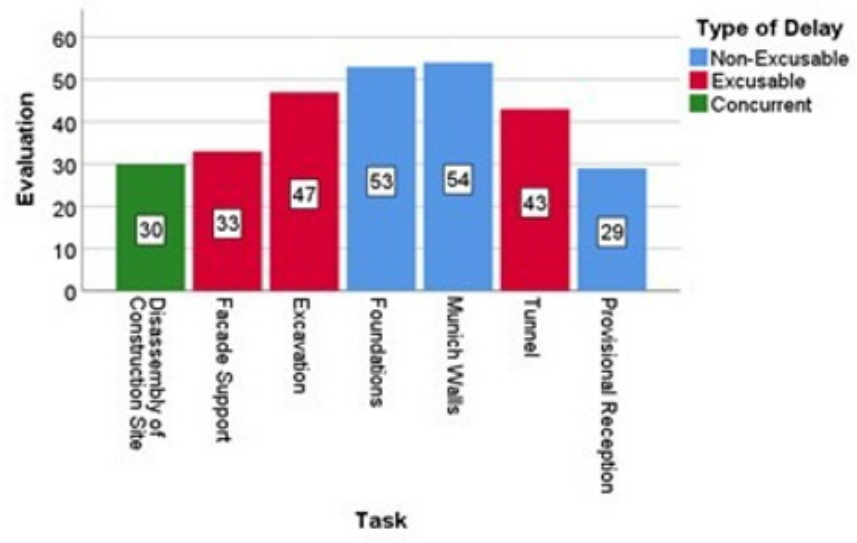

Figure 13: Evaluation by Task by Type of Delay.

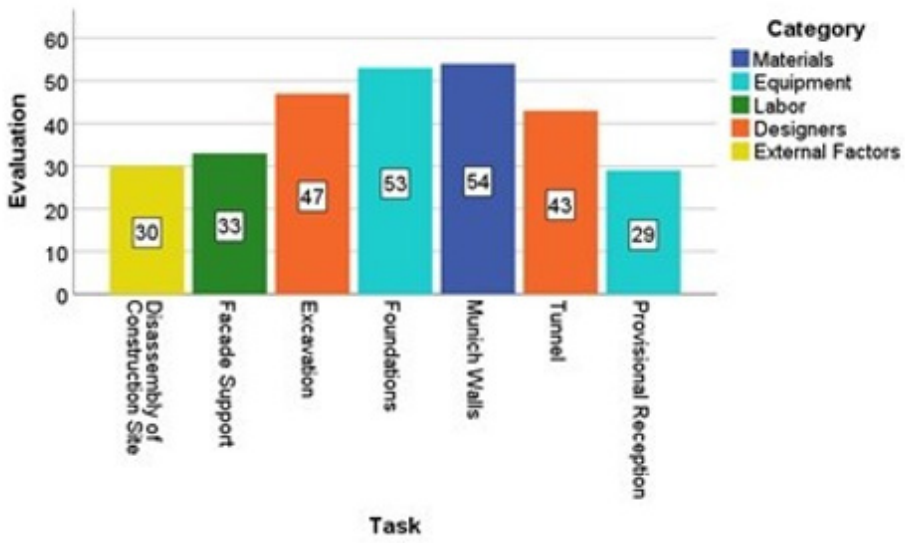

Figure 14: Evaluation by Task by Category.

The category of delay in the excavation and the tunnel tasks has been associated with the design team because the type of soil existing in the construction site did not corresponded to the one planned in the design. Thus, that fact required changings on the planning of this critical task. It should be noted that, although the task of supporting the facade was labor responsibility, it has been classified as excusable, since the welding of the metallic profiles was an extra task and has not been properly verified by the consultors. The disassembly of the construction site has been classified in the category of external factors due to limited accesses and the restrictions imposed by the municipality for the entry and exit of vehicles, which aggravated an already time-consuming process. The provisional reception has been classified in the equipment category, and the reason is that to perform this critical task it is required that all equipment should not be at the construction site (Figure 15).

The dispersion graph with adjustment lines allowed to identify that the tunnel task presents a risk of delay higher than the average of excusable type. Despite this task, to obtain a positive evaluation is extremely important to the dialogue with the design team and to perform the daily control on site construction so that this task 
does not represent a major extension in deadline. It also allowed to clarify that the non-excusable delays are those that comprise tasks with higher risk of delay in construction, which is a positive indicator and shows that the contractor should be able to solve the problem. The task of provisional reception and facade sup- port represent a risk of delay below average (Figure 16).

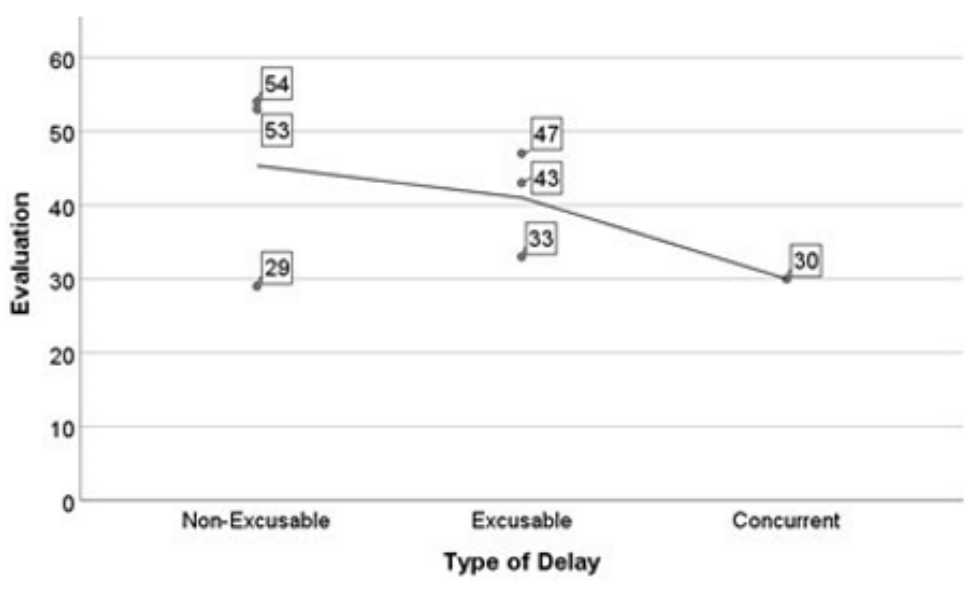

Figure 15: Simple Dispersion with Evaluation Adjustment.

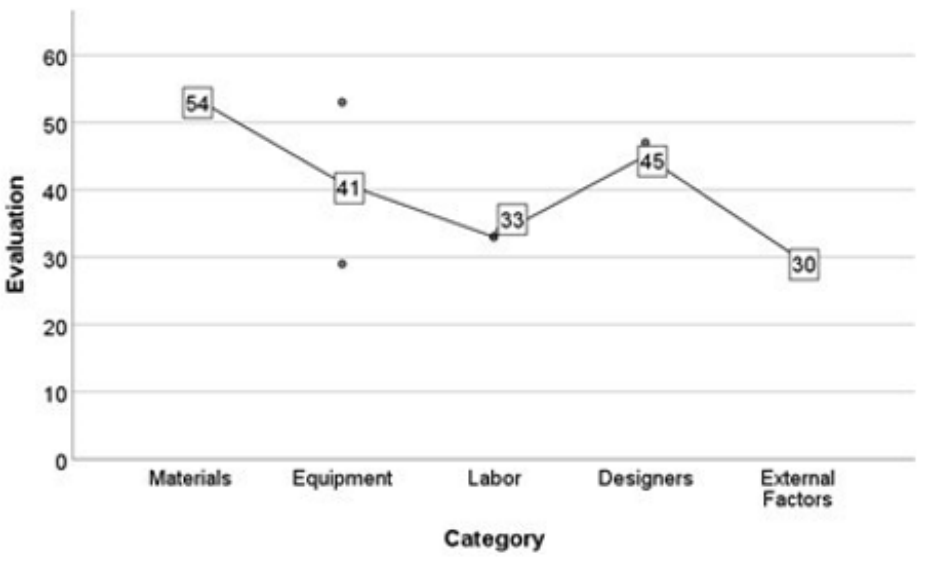

Figure 16: Simple Dispersion with Evaluation Adjustment Lines by Category.

The categories that present the greatest constraints for scheduled execution of the construction are mate- rials, designers and equipment. As previously mentioned, the materials category presents great constraints due to the task related to the Munich walls having a higher risk of delay. For this task it is mandatory to be very accurate on the expected date of materials' deliver on site. The delay presented in this critical task is directly influenced by the market offer at the moment of task execution and cannot be imputed directly to the own- er, as well as to the consultors and contractors. However, indirect decisions regarding the materials and solutions selection are a constraint in the global execution time with direct influence in this critical task. It can be concluded through the dispersion graphic (Figure 16) with line of evaluation by category that external factors and labor were the elements that caused minor delays in the critical tasks of the work.

\section{Conclusions}

The objective of this paper was to identify the main causes of delay that affect buildings construction in Portugal. A literature review and an internship were conducted do identify the cause of delays. Although this study merely focused on the delay problem in building construction in Portugal, its findings are beneficial to other countries around the world. The identification, analysis and evaluation of the constraints responsible for the cause of delays, will be an asset to reduce one of the major problems in today's civil construction industry, that is the non- compliance of deadlines. This has been identified as the main reason for the lack of competitiveness in the sector [45]. Identifying construction constraints, subsequently grouping them by the type of delay and category, performing a quantitative evaluation and their hierarchy 
in the planning and programming phase is a simple and effective way to mitigate and/or avoid delays to occur in the execution tasks [40]. It should be noted that some are constraints difficult to predict, such as the actual COVID-19 pan- demic, which had an extremely negative impact on the execution of the work, particularly in "The Largo Hotel".

The analysis performed in the scope of this study allowed to identify that the different types of building have contrasting constraints. In the case of the residential building there is a greater concern with the architectural works of finishing surfaces which implies that this type of work is more susceptible to delays, when compared to the industrial building typology, which does not require such critical task. In addition, the latter types of buildings are generally implemented in areas with fewer clusters of people and buildings, allowing easier access as well as facilitated construction site implementation. Currently, owing to a shortage of qualified labor workforce for civil construction, it is crucial to the companies to adopt new and better softwares which allows them to assemble a worker planning that is more effective and detailed [39].

Also, the existence of errors and/or omissions in the design phase, often results in delays leading to prolonged interruptions in the execution work. Additionally, this error and/or omissions are related to constructive solutions that are usually incompatible with the reality and the non- identification of changes after correction. So, all together increase the probability of delays to occur in construction, therefore, results in a decrease the expected profits $[5,7,42]$. In sum, it is important for construction companies to approve innovative planning and programming systems, to have specialized technicians to make planning execution and identify constraints $[39,41]$. Furthermore, it will be important that contractors do not depend on subcontractors $[4,5]$. However, with a shortage of labor, this is an aspect that will be difficult to change in the near future.

\section{Acknowledgement}

None.

\section{Conflicts of Interest}

No conflict of interest.

\section{References}

1. EI Contractors (2017) Volume of Turnover.

2. Vlachová K (2019) Lost in transition, found in recession? Satisfaction with democracy in Central Europe before and after economic crises. Communist Post-Communist Stud. 52(3): 227-234.

3. Borges A, Petri SM (2013) Indicadores de desempenho da construção civil - um pesquisa na literatura internacional Indicadores de desempenho da construção civil - um pesquisa na literatura internacional. XX Congr Bras Custos. p.16.

4. Chen GX, Shan M, Chan APC, Liu X, Zhao YQ (2019) Investigating the causes of delay in grain bin construction projects: the case of China. Int J Constr Manag.19(1): 1-14
5. Sambasivan M, Soon YW (2007) Causes and effects of delays in Malaysian construction industry. Int J Proj Manag. 25(5): 517-526.

6. Gebrehiwet T, Luo H (2017) Analysis of Delay Impact on Construction Project Based on RII and Correlation Coefficient: Empirical Study. 196: 366-374.

7. Alsuliman IA (2019) Causes of delay in Saudi public construction projects. Alexandria Eng J. 58(2): 801-808.

8. Alaghbari W, Kadir MRA, Salim A, Ernawati (2007) The significant factors causing delay of building construction projects in Malaysia. Eng Constr Archit Manag. 14(2): 192-206.

9. Couto JP (2007) The Consequences of Failure to Meet Deadlines. Universidade do Minho.

10. Shehu Z, Endut IR, Akintoye A, Holt GD (2014) Cost overrun in the Malaysian construction industry projects: A deeper insight. Int J Proj Manag. 32(8): 1471-1480.

11. Sharan Kumar K, Narayanan RM (2020) Review on construction risk and development of risk management procedural index - A case study from Chennai construction sector. Mater Today Proc.

12. Dziadosz A, Tomczyk A, Kapliński O (2015) Financial Risk Estimation in Construction Contracts. in Procedia Engineering. 122: 120-128.

13. Oghenekevwe 0, Olusola 0, Chukwudi US (2014) Assessment of the impact of inflation on construction material prices in Nigeria. PM World

14. Moynihan GP, Al Zarrad MA (2015) Application of Hedging Principles to Materials Price Risk Mitigation in Construction Projects. Int J Constr Eng Manag. 4(5): 180-190.

15. Varghese, Xavier AS (2013) Study on Causes and Effects of Change Orders in Construction Sites. Int J Sci Res. 9(4).

16. Khalid FJI (2019) The Impact of Poor Planning and Management on the Duration of Construction Projects: A Review. Multi-Knowledge Electron Compr J Educ Sc. Publ. pp.161-181.

17. Gamil Y, Rahman IA (2017) Identification of causes and effects of poor communication in construction industry: A theoretical review. Emerging Science Journal. 1(4)

18. Mohammed SR, Naji HI, Ali RH (2019) Impact of the Feasibility Study on the Construction Projects. in IOP Conference Series: Materials Science and Engineering 518(2).

19. Gazder U, Khan RA (2018) Effect of Organizational Structures and Types of Construction on Perceptions of Factors Contributing to Project Failure in Pakistan. Mehran Univ Res J Eng Technol. 37(1)

20. Erdogan B, Anumba CJ, Bouchlaghem D, Nielsen Y (2008) Collaboration Environments for Construction: Implementation Case Studies. J Manag Eng 24(4)

21. Oseghale BO, Dr Abiola-Falemu JO, Oseghale GE (2015) An Evaluation of Skilled Labour shortage in selected construction firms in Edo state, Nigeria Am J Eng Res. 4(1).

22. Rahman MM, Yap YH, Ramli NR, Dullah MA, Shamsuddin MSW (2017) Causes of shortage and delay in material supply: A preliminary study. in IOP Conference Series: Materials Science and Engineering.

23. Amarasekara WDL, Perera BAKS, Rodrigo MNN (2018) Impact of Differing Site Conditions on Construction Projects. J. Leg. Aff. Disput. Resolut Eng Constr.

24. Aslam M, Baffoe Twum E, Saleem F (2019) Design Changes in Construction Projects - Causes and Impact on the Cost. Civ Eng J. 5(7): 1647-1655.

25. Dosumu OS, Aigbavboa CO (2017) Impact of Design Errors on Variation Cost of Selected Building Project in Nigeria. in Procedia Engineering. 196: 847-856 
26. Smith J, Jaggar D, Love P, Olatunji OA (2016) Building cost planning for the design team (3rd edn.).

27. Rauzana A (2016) Causes of Conflicts and Disputes in Construction Projects. IOSR J Mech Civ Eng. 13(5): 44-48.

28. Damoah IS, Kumi DK (2018) Causes of government construction projects failure in an emerging economy: Evidence from Ghana. Int J Manag Proj Bus.

29. Liu AMM, Lam BC, Fellows R (2006) Bureaucratic Culture in Public and Private Construction Project Organisations. Int J Constr Manag. 6(1): 8195.

30. Rizqa E Ya, Abusharar SW (2014) Assessment of the Impacts of Construction Projects on the Environment in the Gaza Strip. Civ Environ Res.

31. Eaves S, Gyi DE, Gibb AGF (2016) Building healthy construction workers: Their views on health, wellbeing and better workplace design. Appl Ergon. 54: 10-18

32. Thomas NIR, Costa DB (2017) Adoption of environmental practices on construction sites. Ambient. Construído. 17(4): 9-24

33. Ansah RH, Sorooshian S, Bin Mustafa S (2018) The 4Ps: A framework for evaluating construction projects delays. Journal of Engineering and Applied Sciences. 13(5): 1222-1227.

34. Nagata MF, Manginelli WA, Lowe JS, Trauner TJ (2018) Types of Construction Delays. Constr Delays. pp.73-82.

35. Trauner TJ, Manginelli WA, Lowe JS, Nagata MF, Furniss BJ (2009) Types of Construction Delays. Constr Delays. pp.25-36.
36. Cox RF, Issa RRA, Ahrens D (2003) Management's perception of key performance indicators for construction. J Constr Eng Manag. 129(2): 142-151.

\section{Constructora San José (2020).}

38. Arditi D, Nayak S, Damci A (2017) Effect of organizational culture on delay in construction. Int J Proj Manag. 35(2): 136-147.

39. Ansah RH, Sorooshian S, Bin Mustafa S, Duvvuru G (2016) An environmental impact framework for evaluating construction projects delays. Proc Int Conf Ind Eng Oper Manag. pp.764-772.

40. Couto I (2006) Influence of delays on the competitiveness of the Portuguese construction industry: national survey on non-compliance with deadlines. National Civil Engineering Laboratory. pp.1-8.

41. Bin I Yang, Kao CK (2012) Critical path effect based delay analysis method for construction projects. Int J Proj Manag. 30(3): 385-397.

42.Głuszak I, Les̈niak A (2015) Construction Delays in Clients Opinion Multivariate Statistical Analysis. Procedia Eng. 123: 182-189.

43. Hamzah I, Khoiry MA, Arshad I, Tawil NM, Che Ani AI (2011) Cause of construction delay - Theoretical framework. Procedia Eng. 20: 490- 495.

44. SPSS (2020).

45. Majid Abd (1997) Non-Excusable Delays in Construction. 